\title{
ESTUDOS BIOQUÍMICOS E HEMATOLÓGICOS EM RATOS SOBRE BIODISPONIBILIDADE DE MINERAIS NUMA DIETA ENRIQUECIDA COM MULTIMISTURA ${ }^{1}$
}

\author{
Hosana Bandeira SANTOS ${ }^{2}$, Marta Suely MADRUGA ${ }^{3, *}$, Francisca Martins BION ${ }^{4}$, \\ Norma Lúcia Marinho ANTUNES ${ }^{4}$, Kardilândia MENDES², Rosa ÀGUIDA²
}

\section{RESUMO}

Com o objetivo de avaliar a influência de uma multimistura no combate à desnutrição em ratos machos Wistar, no que se refere a biodisponibilidade mineral, foi realizado um estudo utilizando 60 animais recém-desmamados dos quais, após depleção por 14 dias, selecionaram-se 12 ratos para formar o Grupo 0 ou Aprotéico, e o restante foi dividido em 4 grupos: I - dieta controle; II - dieta creche; III - dieta creche enriquecida com 1,2g de Multimistura e IV - dieta creche enriquecida com 2,4g de Multimistura. No geral, o acréscimo de multimistura, mesmo em concentração dobrada, não acarretou diferenças nos níveis séricos de minerais analisados. Em relação à série vermelha, os Grupos estavam dentro da faixa de normalidade. As plaquetas apresentaram-se em maior número no Grupo I e, em menor, no Grupo 0. Na avaliação da série branca, os leucócitos apresentaram menor número no Grupo 0. A diferenciação celular não apresentou nenhuma alteração. Logo, observou-se que as séries vermelha e branca não sofreram alteração com a adição do suplemento à dieta.

Palavras-chave: Multimistura; biodisponibilidade; ratos; minerais.

\section{SUMMARY}

BIOCHEMICAL AND HEMATOLOGICAL STUDIES IN RATS INVOLVING MINERAL BIOAVAILABILITY IN A DIET SUPPLEMENTED WITH "MULTIMISTURA". This work has been aimed to evaluate the influence of a "multimistura" against the malnutrition of Wistar male rats, in relation to the use of minerals. Sixty suckling male rats were submitted to 14 days of malnutrition and after this period, 12 rats were selected to form the group "O" or non-proteic, the others were divided into 4 groups: I - control diet of casein; II - crèche diet; III - crèche diet plus $1.2 \mathrm{~g}$ of multimistura; IV - crèche diet plus $2.4 \mathrm{~g}$ of multimistura. In general, the addition of multimistura to the crèche diet, even in double quantities, did not affect the seric concentrations of minerals analysed. The analysis of blood red cells showed that groups presented values in the limits of normality. The higher number of plackets was observed in group I and the lower in group O. The leukocyte number was lower in group $\mathrm{O}$. The cellular differentiation did not present any modification. From the data it could be observed that the red and white series were not affected by addition of "multimistura" to the diet.

Keywords: "Multimistura"; bioavailability; Wistar rats; minerals.

\section{1 - INTRODUÇÃO}

No Brasil, a alimentação alternativa se constitui numa proposta de um conjunto de práticas alimentares que compreende principalmente a valorização de determinados alimentos já amplamente consumidos e o uso de alimentos não convencionais. A partir de 1986, a prática da alimentação alternativa foi incorporada à rotina de trabalho de algumas entidades governamentais e não governamentais, tais como Pastoral da Criança (CNBB) e Fundação Nacional de Saúde, resultando numa diminuição no quadro de desnutrição nacional [25].

Dentro do Programa de Alimentação Alternativa nasceu a Multimistura, que tem sido amplamente divulgada e utilizada em todo território nacional e, como seu uso tem sido bastante questionado, tornam-se necessárias informações mais completas sobre a compo-

\footnotetext{
Recebido para publicação em 04/04/2003. Aceito para publicação em 12/07/2004 (001093).

2. Hospital Universitário Lauro Wanderley (HULW). Universidade Federal da Paraíba. Campus I. João Pessoa, Paraíba/PB, Brasil. E-mail: shiae@openline.com.br

3. Departamento de Tecnologia Química e de Alimentos, Centro de Tecnologia, Universidade Federal da Paraíba (DTQA/CT/UFPB). Campus I, 58059-900, João Pessoa, Paraíba/PB, Brasil.E-mail:msmadruga@uol.com.br 4. Departamento de Nutrição, Universidade Federal de Pernambuco (DN/ UFPE).

* A quem a correspondência deve ser enviada.
}

sição química, a presença de fatores anti-nutricionais e/ou tóxicos, valores biológicos e a biodisponibilidade de minerais presentes na mesma.

A composição dos alimentos é uma indicação muito significante do seu valor nutritivo, contudo não é suficiente para uma caracterização completa do ponto de vista nutritivo, isso porque, raríssimos são os nutrientes que, contidos nos alimentos, tornam-se totalmente disponíveis ao organismo após ingestão destes. A porção disponivel de qualquer nutriente é aquela que é absorvida em uma forma que possa ser utilizada pelo organismo em seu metabolismo celular. Os fatores mais importantes que interferem na biodisponibilidade dos nutrientes são: digestibilidade, absorção, complexação e presença de substâncias tóxicas. Em relação aos minerais, existe uma grande variação de disponibilidade biológica que depende, principalmente: da natureza química do composto mineral; da complexação com outras substâncias contidas nos alimentos; da natureza química do composto formado; e da competição de dois ou mais elementos pelo mesmo sítio de ação ou mecanismo de absorção [24].

A importância da determinação da biodisponibilidade de minerais em dietas está centralizada no estabelecimento das recomendações de ingestão desses elementos em função das necessidades dos indivíduos. Assim, os estudos da biodisponibilidade de nutrientes devem ser específicos para cada país, tendo em vista a grande diversidade de dietas e de indivíduos [6]. 
Várias metodologias têm sido empregadas para a determinação da biodisponibilidade, como: depleção/ repleção realizadas tanto em animais de laboratório como em humanos voluntários; isótopos radioativos, usados tanto em animais como no ser humano, porém excluindo-se crianças e mulheres em idade fértil; técnicas in vitro utilizando-se culturas de células; e métodos mais avançados, como a utilização de isótopos estáveis dos grupos de risco como crianças, gestantes e lactentes podem participar [14].

Este estudo foi realizado com o objetivo de avaliar a influência de uma Multimistura no que se refere à biodisponibilidade mineral em animais de laboratório.

\section{2 - MATERIAIS E MÉTODOS}

\section{1 - Animais}

Foram utilizados 60 ratos machos da linhagem Wistar provenientes da colônia do Biotério de Criação do Departamento de Nutrição da Universidade Federal de Pernambuco, desmamados aos 21 dias de idade, com

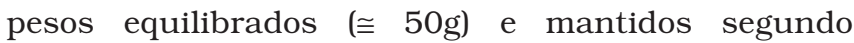
MERUSSE \& LAPICHIK [14]. Todos os animais receberam dieta aprotéica por 14 dias; ao final desse período, selecionaram-se 12 ratos para constituir o Grupo 0 (aprotéico); os 48 restantes foram divididos em 4 grupos de 12 animais, que passaram a alimentar-se, por 28 dias, com diferentes dietas.

\section{2 - Dietas}

Foram preparados cinco tipos de dietas: Grupo 0 (Dieta Aprotéica); Grupo I (Dieta Controle-Caseína); Grupo II (Dieta Creche); Grupo III (Dieta Creche $+1,2 \mathrm{~g}$ de Multimistura); Grupo IV (Dieta Creche $+2,4 \mathrm{~g}$ de Multimistura). As dietas foram confeccionadas semanalmente, no Laboratório de Nutrição Experimental do Departamento de Nutrição da UFPE, e oferecidas diariamente aos animais, em quantidade suficiente para garantir o consumo ad libitum. Os teores de vitaminas, sais minerais, fibras e demais nutrientes foram equilibrados segundo as recomendações da AIN 93 para o rato [20]. Com exceção da dieta aprotéica, as demais dietas compuseram-se por $\pm 10 \%$ de proteína, que é a quantidade necessária para ratos em desenvolvimento. A dieta creche é o resultado do ajuste de uma dieta utilizada em uma creche levando em consideração as necessidades dos ratos na fase de crescimento. Utilizou-se como base uma dieta suplementada com $5 \mathrm{~g}$ de multimistura per capita, oferecida a crianças na faixa etária de 2 a 6 anos, em uma creche no município de João Pessoa, que foi o resultado do inquérito recordatório realizado por profissionais do Departamento de Nutrição da Universidade Federal da Paraíba. A dieta creche foi adicionada de dois níveis de multimistura, que corresponderam a $1,2 \mathrm{~g} / \%$ e $2,4 \mathrm{~g} / \%$.

\section{3 - Multimistura}

A multimistura utilizada neste estudo contém em sua formulação $47,5 \%$ de farelo de trigo; $47,5 \%$ de fubá de milho; 4\% (em quantidades proporcionais) de pó de sementes de melão, gergelim, abóbora e amendoim; $0,5 \%$ de pó da folha de mandioca e $0,5 \%$ de pó da casca de ovo.

\section{4 - Análises da composição mineral}

Foram determinados o cálcio, o ferro, o magnésio, o fósforo, o sódio e o potássio, por espectrometria de emissão atômica por Plasma indutivamente acoplado (ICPAES), marca BAIRD, modelo ICP 2000, segundo ANGELUCCI \& MANTOVANI [1].

\section{5 - Ensaios biológicos}

O método utilizado para a avaliação da biodisponibilidade foi a de depleção/repleção segundo a técnica de Osborne \& Mendell, modificada por PESSOA et al. [16].

\section{6 - Análises bioquímicas}

Através de punção cardíaca, no momento do sacrifício, coletaram-se amostras de sangue, que foram colocadas em tubos de 2,5mL contendo gel separador (Microtainer- Becton- Dickinson) e centrifugados em centrífuga BIO ENG Modelo BE-4.000, por 10 minutos, a 3.500rpm, obtendo-se, assim, o soro.

As análises bioquímicas constaram da dosagem de proteínas totais, da albumina, do ferro sérico, da capacidade latente de ligação do ferro (CLLF), da transferrina, do cálcio total, fósforo, sódio, potássio e magnésio.

As determinações de proteínas totais, da albumina, do ferro sérico, da capacidade latente de ligação do ferro (CLLF), da transferrina, do cálcio total, fósforo e magnésio realizaram-se por espectrofotometria em analisador bioquímico automatizado COBAS MIRA PLUSROCHE DIAGNOSTIC SYSTEM. O sódio e o potássio foram determinados por fotometria de chama no fotômetro 7000 Tecnow. A ferritina foi determinada por fluorimetria no OPUS PLUS-BEHRING DIAGNÓSTICA.

A capacidade total de ligação do ferro (CTLF), o índice de saturação da transferrina (IST) e as globulinas foram calculadas segundo as equações 1, 2 e 3, respectivamente: Equação 1 (CTLF = Fe + CLLF); Equação 2 $(\mathrm{IST}=(\mathrm{Fe} / \mathrm{CTLF}) \times 100)$; Equação 3 (Globulinas = Proteínas totais - Albumina).

\section{7 - Análises hematológicas}

O sangue foi coletado em microtubos de $500 \mathrm{~mL}$ heparinizados, e as análises constaram do estudo das séries vermelha (eritrograma) e branca (leucograma). No eritrograma foi realizada a contagem de plaquetas e de hemácias, a determinação do hematócrito, da hemoglobina, do VCM-volume corpuscular médio, da HCMhemoglobina corpuscular média, e da CHCM-concentração da hemoglobina corpuscular média. No leucograma contaram-se os leucócitos e fez-se a contagem da diferenciação celular. Essas determinações foram realizadas no analisador celular COBAS ARGOS 50 ROCHE. Os esfregaços sangüíneos foram corados 
automaticamente no HEMATEL 200 e analisados em microscópio Olympus.

\section{8 - Análises estatísticas}

As análises bioquímicas foram realizadas em triplicatas, e os dados bioquímicos e hematológicos foram submetidos à análise de variância, através do Statistical Analysis System [23], obedecendo a um delineamento inteiramente casualizado com cinco tratamentos e doze repetições.

\section{3 - RESULTADOS E DISCUSSÃO}

Na Tabela 1 estão listados os valores dos minerais determinados na ração creche e na multimistura. Ao analisar-se essa tabela, observa-se que a multimistura é mais rica em minerais do que a ração creche, constituindo, aquela, uma excelente fonte de ferro, de cálcio e de magnésio, como também uma boa fonte de potássio e fósforo, apresentando baixas proporções de sódio.

TABELA 1. Teores de minerais da ração creche e da multimistura expressos em $\mathrm{mg} / 100 \mathrm{~g}$.

\begin{tabular}{lcc}
\hline \multirow{2}{*}{ DETERMINAÇÕES } & \multicolumn{2}{c}{ ALIMENTOS } \\
\cline { 2 - 3 } & Ração Creche & Multimistura \\
\hline Ferro & 3,04 & 7,59 \\
Cálcio & 73,00 & 336,00 \\
Fósforo & 155,00 & 536,00 \\
Magnésio & 52,90 & 221,00 \\
Sódio & 513,00 & 6,60 \\
Potássio & 439,00 & 637,00 \\
\hline
\end{tabular}

SANT'ANA et al. [21], ao analisar uma multimistura difundida pela Secretaria de Abastecimento de Belo Horizonte-MG que continha 33\% de fubá; 33\% de farelo de trigo; $1 \%$ de casca de mandioca e $1 \%$ de casca de ovo encontrou: 444mg de cálcio, 154,4mg de magnésio e 5mg de ferro/100g; o INSTITUTO DE TECNOLOGIA DE ALIMENTOS [11] reportou resultados semelhantes ao analisar uma multimistura: 487,43mg de cálcio; 460,37mg de potássio; 396,42mg de fósforo; 130,67mg de magnésio e 4,23mg de ferro/100g de alimento; portanto, a multimistura em estudo está com teores de minerais compativeis com outras formulações.

Considerando-se as proporções de multimistura utilizadas no Hospital Universitário Lauro Wanderley (HULW) da Universidade Federal da Paraíba (5g/dia) e as recomendações diárias para crianças na faixa etária de 1 a 10 anos RDA [19], observa-se que a mesma contribuiu com $4 \%$ das necessidades diárias de ferro, $2,1 \%$ de cálcio, 7,4\% de magnésio, $0,08 \%$ de sódio, $2,1 \%$ de potássio e 3,3\% de fósforo.

Os resultados de proteínas totais e frações para os diferentes tratamentos estão apresentados na Tabela 2.
TABELA 2. Teores séricos de proteínas totais, albuminas e globulina, expressos em g/dL.

\begin{tabular}{cccccc}
\hline AVALIAÇÕES & GRUPO 0 & GRUPO I & aRUPO II & GRUPO III & GRUPO IV \\
\cline { 2 - 6 } BIOQUÍMICAS & Aprotéico & Controle & Creche & $\begin{array}{c}\text { Jreche+1,2g de } \\
\text { multimistura }\end{array}$ & $\begin{array}{c}\text { Creche+2,4g } \\
\text { le multimistura }\end{array}$ \\
\hline ProteínasTotais & $4,19^{c}$ & $5,53^{a}$ & $5,03^{\mathrm{b}}$ & $5,02^{\mathrm{b}}$ & $4,88^{\mathrm{b}}$ \\
Albumina & $2,27^{\mathrm{c}}$ & $3,01^{\mathrm{a}}$ & $2,83^{\mathrm{ab}}$ & $2,63^{\mathrm{b}}$ & $2,68^{\mathrm{b}}$ \\
Globulina & $1,93^{\mathrm{b}}$ & $2,43^{\mathrm{a}}$ & $2,27^{\mathrm{a}}$ & $2,38^{\mathrm{a}}$ & $2,23^{\mathrm{a}}$ \\
\hline
\end{tabular}

Nas linhas, valores seguidos pela mesma letra não diferem significativamente, pelo teste de Tukey, ao nivel de $5 \%$ de probabilidade.

De acordo com essa tabela, observa-se que os valores de proteínas totais foram estatisticamente diferentes entre os grupos avaliados. O Grupo Aprotéico foi o que apresentou menor valor $(4,19 \mathrm{~g} / \mathrm{dL})$, e o Controle, o maior valor $(5,53 \mathrm{~g} / \mathrm{dL})$; porém, não houve diferença estatística entre os grupos alimentados com a ração creche e os suplementados. A adição de multimistura não alterou os valores de proteínas totais. $\mathrm{O}$ mesmo comportamento ocorreu com a determinação de albumina, entretanto os valores de globulina só diferiram estatisticamente em relação ao Grupo Aprotéico, que obteve menor valor.

A influência da suplementação alimentar com multimistura nos valores médios de proteínas totais e frações foi observada por PRATES [18] em 41 crianças na faixa etária de 2 a 5 anos, pertencentes a um Centro Infantil de Belo Horizonte-MG. Todas receberam a dieta habitual da creche, sendo que, à dieta do grupo experimental, foi adicionada $12,5 \mathrm{~g}$ de multimistura. $\mathrm{O}$ sangue das crianças foi coletado no início e no final do experimento. Segundo essa autora, a suplementação alimentar não interferiu no estado nutricional.

Na Tabela 3, estão expressos os valores médios dos elementos químicos dosados no sangue dos ratos submetidos aos diferentes tratamentos.

TABELA 3. Teores séricos médios de sódio, potássio, cálcio total, fósforo e magnésio, expressos em $\mathrm{mEq} / \mathrm{dL}$, nas rações dos grupos experimentais.

\begin{tabular}{cccccc}
\hline AVALIAÇÕES & GRUPO 0 & GRUPO I & GRUPO II & GRUPO III & GRUPO IV \\
\cline { 2 - 6 } BIOQUÍMICAS & Aprotéico & Controle & Creche & $\begin{array}{c}\text { Creche+1,2g } \\
\text { de multimistura }\end{array}$ & $\begin{array}{c}\text { Creche }+2,4 g \\
\text { de multimistura }\end{array}$ \\
\hline Sódio & $139,42^{\mathrm{bc}}$ & $137,33^{\mathrm{bc}}$ & $141,75^{\mathrm{ab}}$ & $144,58^{\mathrm{a}}$ & $135,00^{\mathrm{c}}$ \\
Potássio & $4,59^{\mathrm{bc}}$ & $4,17^{\mathrm{c}}$ & $4,78^{\mathrm{b}}$ & $5,32^{\mathrm{a}}$ & $4,93^{\mathrm{ab}}$ \\
Cálcio Total & $9,63^{\mathrm{bc}}$ & $12,34^{\mathrm{a}}$ & $9,41^{\mathrm{c}}$ & $9,99^{\mathrm{b}}$ & $10,09^{\mathrm{b}}$ \\
Fósforo & $7,24^{\mathrm{ab}}$ & $7,96^{\mathrm{ab}}$ & $8,28^{\mathrm{a}}$ & $6,81^{\mathrm{b}}$ & $7,93^{\mathrm{ab}}$ \\
Magnésio & $1,63^{\mathrm{d}}$ & $2,13^{\mathrm{c}}$ & $1,98^{\mathrm{cd}}$ & $3,04^{\mathrm{a}}$ & $2,62^{\mathrm{b}}$ \\
\hline
\end{tabular}

Nas linhas, valores seguidos pela mesma letra não diferem significativamente, pelo teste de Tukey, ao nivel de $5 \%$ de probabilidade.

Os valores de sódio foram estatisticamente iguais entre o Grupo Aprotéico e o Controle; a depleção não afetou a concentração de sódio nos animais. O maior valor de sódio ocorreu no Grupo III e, curiosamente, o menor, no Grupo IV. A multimistura em estudo é muito pobre em sódio, o que é um bom prognóstico, e a adição da mesma na dieta não interferiu significativamente na absorção final. 
O potássio apresentou-se com valores diferentes em todos os grupos. O Grupo Controle apresentou menor teor $(4,17 \mathrm{mEq} / \mathrm{L})$, e o Grupo III, o maior $(5,32 \mathrm{mEq} / \mathrm{L})$. A multimistura tem uma boa concentração de potássio e, nos grupos suplementados, houve uma maior concentração desse íon.

A concentração de sódio e potássio dos animais em estudo está dentro da faixa de normalidade preconizada por outros autores que utilizaram ratos alimentados com rações comerciais [3, 17].

A concentração sérica de cálcio foi maior no Grupo Controle, observando-se menor valor no Grupo Creche, e este, por sua vez, apresentou uma menor concentração que o Grupo Aprotéico, embora esses resultados não fossem estatisticamente diferentes. Nos grupos suplementados, a multimistura melhorou os niveis de cálcio, mesmo não havendo diferença estatística entre os mesmos.

Em relação aos níveis séricos de fósforo, não ocorreu diferença estatística entre os Grupos 0, I, II e IV. Curiosamente, o Grupo Creche (II) foi o que apresentou maior valor $(8,28 \mathrm{mg} / \mathrm{dL})$, e o Grupo III, o menor $(6,81 \mathrm{mg} / \mathrm{dL})$. Tendo a multimistura consideráveis teores de fósforo, esperava-se que os dois grupos suplementados obtivessem maiores valores em relação ao grupo alimentado unicamente com a ração creche.

Apesar das diferenças estatísticas, os resultados estão dentro da faixa de normalidade para ratos [3, 17]. Isso talvez decorra da farta distribuição do fósforo nos alimentos, impossibilitando, assim, uma dieta inadequada [24].

Ao analisar-se o magnésio, observa-se que a menor concentração foi apresentada pelo grupo aprotéico, confirmando o que foi relatado por SARTOR et al. [22], na desnutrição protéico-calórica, podendo-se relacionar a redução do magnésio plasmático ao menor teor protéico do desnutrido, conseqüentemente ocorrendo redução do magnésio ligado à proteína.

Os valores de magnésio dos grupos suplementados foram maiores do que os do Grupo Controle. O Grupo III apresentou o maior valor $(3,04 \mathrm{mg} / \mathrm{dL})$; conclui-se, assim, que a multimistura contribuiu para elevar os niveis de magnésio nos animais estudados, e que o cálcio presente na dieta não interferiu na absorção do mesmo.

A literatura relata a interação existente entre cálcio e magnésio. Eles interagem na regulação da tonicidade dos vasos sangüíneos; o cálcio age contraindo-os, enquanto o magnésio relaxa e dilata os vasos; esses íns também competem pela absorção no intestino [4, $5,12,15]$.

Na Tabela 4, estão apresentados os resultados das determinações que compõem o perfil do ferro tanto na forma de depósito (ferritina) como na de transporte (transferrina).

De forma geral, observa-se que os animais em estudo não apresentaram carência de ferro no tempo proposto do estudo. Curiosamente, o Grupo Aprotéico apre- sentou um valor médio de ferro sérico maior que o dos grupos alimentados com a ração creche e o dos suplementados, no entanto essa diferença não foi significativa. Como era esperado, o Grupo Controle apresentou maior concentração férrica. Os demais índices, como Capacidade Latente de Ligação do Ferro, Capacidade Total de Ligação do Ferro e Índice de Saturação da Transferrina, foram compativeis com os resultados de ferro sérico. Mesmo não havendo diferença estatística entre os Grupos II, III e IV, os valores médios de ferro sérico diminuíram com a suplementação, aumentando, assim, a Capacidade Latente de Ligação do Ferro.

TABELA 4. Teores de ferro, Capacidade Latente de Ligação do Ferro (CLLF), Capacidade Total de Ligação do Ferro (CTLF), Índice de Saturação da Transferrina (IST), Ferritina e transferrina no sangue dos animais dos grupos experimentais.

\begin{tabular}{cccccc}
\hline AVALIAÇÕES & GRUPO 0 & GRUPO I & GRUPO ॥ & GRUPO III & GRUPO IV \\
\cline { 2 - 6 } BIOQUIMICAS & Aprotéico & Controle & Creche & $\begin{array}{c}\text { Creche+1,2g } \\
\text { de multimistura }\end{array}$ & $\begin{array}{c}\text { Creche+2,4 } \\
\text { de multimistura }\end{array}$ \\
\hline Ferro $(\mu \mathrm{g} / \mathrm{dL})$ & $141,50^{\mathrm{b}}$ & $254,00^{\mathrm{a}}$ & $124,25^{\mathrm{b}}$ & $118,50^{\mathrm{b}}$ & $122,50^{\mathrm{b}}$ \\
CLLF $(\mu \mathrm{g} / \mathrm{dL})$ & $204,75^{\mathrm{b}}$ & $238,00^{\mathrm{ab}}$ & $283,50^{\mathrm{a}}$ & $267,33^{\mathrm{ab}}$ & $258,75^{\mathrm{ab}}$ \\
CTLF $(\mu \mathrm{g} / \mathrm{dL})$ & $346,25^{\mathrm{c}}$ & $465,92^{\mathrm{a}}$ & $407,75^{\mathrm{b}}$ & $385,83^{\mathrm{b}}$ & $381,17^{\mathrm{bc}}$ \\
IST $(\%)$ & $41,75^{\text {ab }}$ & $53,20^{\mathrm{a}}$ & $31,25^{\mathrm{b}}$ & $30,58^{\mathrm{b}}$ & $32,54^{\mathrm{b}}$ \\
Ferritina* $(\mathrm{ng} / \mathrm{dL})$ & $<1$ & 4,08 & 3,63 & $<1$ & $<1$ \\
Transferrina & $119,3^{\mathrm{b}}$ & $134,1^{\mathrm{a}}$ & $121,6^{\mathrm{b}}$ & $119,3^{\mathrm{b}}$ & $121,7^{\mathrm{b}}$ \\
(mg/dL) & & & & &
\end{tabular}

Nas linhas, valores seguidos pela mesma letra não diferem significativamente, pelo teste de Tukey, ao nivel de $5 \%$ de probabilidade. * Valores dados pela média.

Nos valores de transferrina não houve diferença estatística entre os grupos 0, II, III e IV; só o Grupo Controle apresentou maior concentração dessa proteína. A ferritina não pôde ser avaliada estatisticamente, pois não foi possível obter-se valores absolutos dos Grupos 0, III e IV, já que a metodologia empregada quantifica a ferritina presente nas amostras; entretanto, a literatura relata a análise quantitativa da ferritina por métodos imunohistoquímicos [8, 13, 26].

Mesmo assim, pôde-se constatar que o Grupo Aprotéico apresentou valores diminuídos devido a uma dieta isenta de proteína; em relação aos Grupos suplementados pode ter havido interferência de alguma substância presente no suplemento. Esses resultados sugerem que métodos isolados são ineficazes para uma avaliação correta nos distúrbios do ferro. Neste estudo, os valores de ferritina demonstraram haver uma deficiência no armazenamento do ferro nos Grupos 0, III e IV.

Os valores médios hematológicos em função dos diferentes tratamentos estão apresentados na Tabela 5. O comportamento da série vermelha foi compativel com os valores do ferro sérico. Embora o Grupo Aprotéico tenha apresentado menores valores, os mesmos não foram estatisticamente diferentes do Grupo Controle, e estão, ambos, dentro da faixa de normalidade estudada por DINIZ et al. [7]. Os grupos II, III e IV não diferiram estatisticamente entre si, porém os suplementados obtiveram maiores valores. Outros autores 
$[2,9]$ também reportaram não ter encontrado diferenças em relação ao hematócrito e à hemoglobina entre grupos suplementados com multimistura.

TABELA 5. Valores médios hematológicos (eritrograma e plaquetas) em função dos diferentes tratamentos.

\begin{tabular}{|c|c|c|c|c|c|}
\hline $\begin{array}{c}\text { AVALIAÇOES } \\
\text { HEMATOLÓGICAS }\end{array}$ & GRUPO 0 & GRUPO I & GRUPO II & GRUPO III & GRUPO IV \\
\hline $\begin{array}{c}\text { (Eritrograma + } \\
\text { Plaquetas) }\end{array}$ & Aprotéico & Controle & Creche & $\begin{array}{c}\text { Creche+1,2g } \\
\text { de multimistura }\end{array}$ & $\begin{array}{c}\text { Creche+2,4g } \\
\text { de multimistura }\end{array}$ \\
\hline Hemácias ${ }^{1}\left(/ \mathrm{mm}^{3}\right)$ & $5.649,2^{b}$ & $5.716,7^{b}$ & $6.391,7^{\mathrm{a}}$ & $6.573,3^{a}$ & $6.500,0^{a}$ \\
\hline Hematócrito (\%) & $34,42^{b}$ & $36,17^{b}$ & $38,08^{a}$ & $38,92^{a}$ & $38,50^{a}$ \\
\hline Hemoglobina (g/dL) & $12,43^{b}$ & $13,2^{b}$ & $13,3^{\text {a }}$ & $13,03^{a}$ & $13,38^{a}$ \\
\hline $\operatorname{VCM}(\mathrm{fL})$ & $60,44^{b}$ & $64,08^{a}$ & $59,75^{b}$ & $59,42^{b}$ & $59,50^{b}$ \\
\hline HCM (pgL) & $21,90^{b}$ & $23,33^{a}$ & $20,83^{\circ}$ & $19,87^{b}$ & $20,50^{\circ}$ \\
\hline $\mathrm{CHCM}(\mathrm{g} / \mathrm{dL})$ & $36,32^{a}$ & $36,01^{a b}$ & $35,17^{\mathrm{bc}}$ & $33,52^{d}$ & $34,33^{\text {cd }}$ \\
\hline Plaquetas ${ }^{1}\left(/ \mathrm{mm}^{3}\right)$ & $614,50^{\circ}$ & $983,92^{\mathrm{a}}$ & $914,33^{a b}$ & $834,42^{b}$ & $841,17^{b}$ \\
\hline
\end{tabular}

No que se refere aos valores das plaquetas, observa-se que foram maiores no Grupo Controle e menores no Aprotéico, que mesmo assim estão dentro da faixa de normalidade [10]. Esse resultado foi compativel, pois a superfície exterior das plaquetas é rica em glicoproteínas, tanto as que estão integradas à membrana da plaqueta como as adsorvidas do plasma.

Na Tabela 6, estão apresentados os valores médios hematológicos (leucograma) dos cinco grupos pesquisados. O leucograma do Grupo Aprotéico obteve o menor número de leucócitos, o que foi de encontro com a dieta utilizada; a ausência de proteína afeta o sistema imunológico. Os demais grupos não apresentaram diferença significativa, apesar do aumento de leucócitos nos grupos suplementados. A diferenciação celular mostrou-se compatível com a literatura [7, 10, 17] não sendo observada variações significativas entre os tratamentos.

TABELA 6. Valores médios hematológicos (leucograma) em função dos diferentes tratamentos.

\begin{tabular}{lccccc}
\hline $\begin{array}{c}\text { AVALIAÇÕES } \\
\text { HEMATOLÓGICAS }\end{array}$ & GRUPO 0 & GRUPO I & GRUPO II & GRUPO III & GRUPO IV \\
\hline (Leucograma) & Aprotéico & Controle & Creche & $\begin{array}{c}\text { Creche+1,2g } \\
\text { de multimistura }\end{array}$ & $\begin{array}{c}\text { Creche+2,4g } \\
\text { de multimistura }\end{array}$ \\
\hline Leucócitos (/mm $)$ & $3.472,8^{\mathrm{b}}$ & $6.358,3^{\mathrm{a}}$ & $6.533,3^{\mathrm{a}}$ & $8.491,7^{\mathrm{a}}$ & $7.225,0^{\mathrm{a}}$ \\
Linfócitos (\%) & $70,92^{\mathrm{b}}$ & $81,08^{\mathrm{a}}$ & $75,42^{\mathrm{ab}}$ & $80,0^{\mathrm{a}}$ & $81,92^{\mathrm{a}}$ \\
Monócitos (\%) & $1,58^{\mathrm{a}}$ & $2,25^{\mathrm{a}}$ & $1,92^{\mathrm{a}}$ & $1,92^{\mathrm{a}}$ & $2,17^{\mathrm{a}}$ \\
Eosinófilos (\%) & $0,42^{\mathrm{a}}$ & $1,33^{\mathrm{a}}$ & $0,67^{\mathrm{a}}$ & $1,25^{\mathrm{a}}$ & $1,00^{\mathrm{a}}$ \\
Neutrófilos Seg. (\%) & $25,42^{\mathrm{a}}$ & $15,17^{\mathrm{b}}$ & $22,00^{\mathrm{ab}}$ & $16,83^{\mathrm{b}}$ & $14,92^{\mathrm{ab}}$
\end{tabular}

Nas linhas, valores seguidos pela mesma letra não diferem significativamente, pelo teste de Tukey, ao nivel de $5 \%$ de probabilidade.

\section{4 - CONCLUSÕES}

Considerando-se os resultados obtidos, pode-se concluir que o acréscimo de multimistura às dietas, mesmo em concentração de $2,4 \mathrm{~g} / 100 \mathrm{~g}$, não apresentou diferenças nos níveis séricos dos minerais analisados, nem tão pouco nas séries hematológicas vermelha e branca. No entanto, a diminuição marcante nos níveis da ferritina, apresentada pelos ratos que receberam ração suplementada com Multimistura, poderá resultar em problemas relacionados a absorção e controle do metabolismo de ferro, quando observados em experimentos a longo prazo.

\section{5 - REFERÊNCIAS BIBLIOGRÁFICAS}

[1] ANGEluCCI, E.; MANTOVANI, D.M.B. Minerais em Alimentos: manual técnico. Campinas: ITAL/SBCTA, 1986. 131p.

[2] BION, F.M.; PESSOA, D.C.N.P.; LAPA, M.A.G.; CARVALHO, M.J. Uso de uma multimistura como suplementação alimentar: estudo em ratos. Arch Lat. Amer. Nutr. v. 47, n. 3, p. 242-247, 1997.

[3] CANADIAN COUNCIL ANIMAL CARE - CCAC. Guide to care and use of experimental animals. Otawa: CCAC, 1984. v. 2. p. 175-189.

[4] CÂNDIDO, L.M.B.; CAMPOS, A.M. Alimentos funcionais uma revisão. Bol. SBCTA, v. 29, n. 2, p. 193-203, 1995.

[5] CHERYAN, M. Phytic acid interactions in food system. CRC. Crit. Rev. Food Sci. Nutr. v. 13, n. 4, p. 964-7, 1980.

[6] COZZOLINO, S.M.F. Biodisponibilidade de minerais. Rev. Nutr. PUCCAMP, v. 10, n. 2, p. 87-98, 1997.

[7] DINIZ, M.F.F.M.; SANTOS, H.B.; MALTA JR. A.; MENDES, K. Parâmetros hematológicos e bioquímicos de camundongos Swiss e ratos Wistar do Biotério do Laboratório de Tecnologia Farmacêutica da Universidade Federal da Paraíba. In: CONGRESSO BRASILEIRO DE ANÁlISES CLÍNICAS, 26, 1999, Goiânia.

[8] ERICKSON, M.K.; PINERO, D.J.; CONNOR, J.R.; BERGAN, J.G.; SIET, T. Regional brain iron, ferritin and transferin concentracions during iron deficiency and iron refletion in developing rats. J. Nutr., v. 127, n. 10, p. 2030-2038, 1997.

[9] FARINI, M.; COSTA, P.V.; CHIAPPINI, C.J.; SOUSA, S.; PONTES, S.Z.B. Indices hematológicos de ratos em uso de multimistura básica do município de QuissamãRJ.. In: CONGRESSO NACIONAL DA SOCIEDADE BRASILEIRA DE ALIMENTAÇÃO E NUTRIÇÃO, 4, 1996, São Paulo. Resumos... São Paulo:SBAN.

[10] HARKNESS, J.E.; WAGNER, J.E. Biologia e Clínica de Coelhos e Roedores 3.ed. São Paulo:Roca, 1993. 238p.

[11] InSTITUTO DE TECNOLOGIA DE ALimentos. Avaliação química e nutricional de farinha composta. Campinas, 1995. 10p.

[12] LOPEZ, H.W.; CONDRAY, C.; BELLANGER, J. Intestinal fermentation lessens the inhibitory effects of phytic acid on mineral utilization in rats. J. Nutr., v. 28 , n. 7 , p. 1192-8, 1998.

[13] LU, J.P.; HAYASHI, K. Transferrin receptor distribution and iron depositon in the hepatic lobule of iron overloaded rats. Biomed. Environ. Sci. v. 9, p. 341-7, 1995.

[14] MERUSSE, J.L.B.; LAPICHIK, V.B.V. Instalações e equipamentos. In: COMISSÃO DE ENSINO DO COLÉGIO BRASILEIRO DE EXPERIMENTAÇÃO ANIMAL. Manual para técnicos em bioterismo. 2.ed. São Paulo:EPM, 1996. 259p.

[15] OHTA, A.; BABA, S.; OHTSUKI, M.; JANG, E.R. In vivo absorption of calcium carbonate and magnesium oxide from the large intesine in rats. J. Nutr. Sci. Vitaminol, v. 43, p. 35-46, 1997.

[16] PESSOA, D.C.N.P.; LAGO, E.S.; FREITAS, L.P.C.G.; 
SILVA, A.M. Misturas de feijão e arroz de alto valor protéico. Rev. Bras. de Pesquisas Méd. e Biol. v. 12, n. 2-3, p. 127-132,1979.

[17] PINHEIRO, D.C.S.N.; FAVALI, C.B.F.; SOUSA FILHO, A.A.; COSTA, P.V. Parâmetros hematológicos de camundongos e ratos do Biotério Central da Universidade Federal do Ceará. Bol. Inf. Cobea, n. 3, p. 6-9, 1997/98.

[18] PRATES, A.C.M. Estudo do farelo de trigo, pó de folha de mandioca e pó de casca de ovo em crianças com risco de desnutrição. Recife, 1998. 60p. Dissertação (Mestrado em Saúde Pública). Universidade Federal de Pernambuco.

[19] RECOMENDED Dietary ALlOWANCES. 10.ed. Nat. Acad. Sci., 1989.

[20] REEVES, P.G.; NIELSEN, F.H.; FAHEY, G.C. AIN-93 Purified diets for laboratory rodents: final report of the American Institute of Nutrition Ad Hoc writing Committee on the reformulation of the AIN-76A rodent diet. J. Nutr. v. 123, n. 10, p. 939-1951, 1993.

[21] SANT'ANA, L.F.R.; COSTA, N.M.B.; FERREIRA, G.; DINIZ, M.F.F.; LAPA, M.A.G. Valor Nutritivo de
"Multimisturas" utilizadas como Alternativa Alimentar. In: CONGRESSO NACIONAL DA SOCIEDADE BRASILEIRA DE ALIMENTAÇÃO E NUTRIÇÃO, 4, 1996, São Paulo. Anais... São Paulo:SBAN.

[22] SARTOR, M.E.A.; NÓBREGA, F.J.; TONETE, S.S.Q.; ADAMO, C. Comportamento do cálcio, fósforo e magnésio em ratas submetidas à desnutrição durante várias etapas no período gestacional. Arch. Latin. Amer. Nutr. v. 32, n. 2, p. 450-462, 1982.

[23] SAS INSTITUTE. SAS user's guide: statistics. Cary, 1985. 956p.

[24] SGARBIERI, V.C. Alimentação e nutrição: fator de saúde e desenvolvimento. Campinas:UNICAMP, 1987.

[25] UNICEF. Alimentação Alternativa. Aspectos Nutricionais e Sociais. O Papel das Instituições. Fortaleza, 1994. 14p.

[26] YEH, K.Y.; ALVAREZ-HERNANDEZ, X.; GLASS, J. Rat intestinal and hepatic ferritin subunit expression during development and after dietary iron freding. Amer. J. Physiol., v. 270, p. 498-505, 1996. 